\title{
ANÁLISIS IDEOLÓGICO Y MODELOS EPISTEMOLÓGICOS
}

Los puntos de vista habituales en la epistemología ligada al desenvolvimiento de la filosofía analítica no suelen ser vistos con simpatía por quienes practican investigaciones en el marco del materialismo histórico. Es tarea fácil encontrar, en textos de estos últimos autores, un desvio o incluso un rechazo frontal de todo cuanto se ha producido en aquel campo. Uno de los criterios más comunes en el fundamento de dicho rechazo consiste en sostener que esa epistemología "académica" supone, por motivos probablemente ideológicos, una extensión ilegítima de tesis surgidas de la consideración de las ciencias naturales a un campo totalmente distinto, tanto, que todo lo que se haya trabajado en él es rigurosamente inaplicable a las ciencias sociáles, hasta el punto de considerar razonable desentenderse por completo de los aportes eventuales de esa epistemología.

En lo que sigue trataremos de mostrar que ese rechazo no es razonable. Primero, porque no es congruente con los análisis concretos que se hacen en el marco del materialismo histórico, ya que esos análisis, hechos por los mismos que explícitamente condenan la epistemología "académica", pueden ser interpretados con los instrumentos de esa epistemología; segundo, porque una "importación" consciente de las doctrinas y, más aun, de los problemas que en la filosofía analítica de la ciencia se han debatido podría servir adecuadamente para diferenciar un "buen" análisis concreto de otro que no lo es, eliminando asf el subjetivismo que habitualmente pesa en las valoraciones de dichos análisis.

\section{I}

Empecemos por determinar cuáles serán los análisis concretos de los que hemos de hablar. Nos interesaremos por aquellos que, constituyen un intento de aplicación de la Teoría de las Ideologias, o sea, aquellos que pretenden mostrar cómo ciertas manifestaciones culturales se explican en función de configuraciones históricas, o en función de grupos sociales o de los antagonismos entre éstos.

Se trata, desde luego, de un interés teórico: los problemas epistemológicos que plantea el análisis ideológico son de otra magnitud que aquellos a los que puede dar lugar un análisis de historia económica. En este último caso operamos en el interior de una única dimensión infraestructural y no nos vemos en la obligación de pensar la dependencia de un nivel (por ejemplo, el del 
pensamiento filosófico o el de la vivencia religiosa) con respecto a otro que le es heterogéneo. Por lo tanto estamos completamente a salvo, sea de tomar por explicaciones lo que son simples analogias entre niveles, sea de reducir ilegítimamente un nivel a no ser sino la emanación del otro. En cambio, el análisis ideológico se encuentra permanentemente acechado por esos peligros. $Y$ justamente por eso es que se vuelve acuciante buscar criterios, siquiera aproximativos, de corrección en el análisis. Después de todo, en algo tiene que reposar la diferencia entre análisis que conectan, por ejemplo, el sesgo que en algunos países de Europa adquirió el calvinismo o la difusión de la filosofía de la Ilustración, con el ascenso de la burguesía (análisis hoy universalmente aceptados), y aquellos otros donde se proclama que el auge del "monólogo interior" en la novelística contemporánea se debe a la crisis de la misma clase social, o donde se sostiene que el espesor tímbrico de la orquesta wagneriana refleja el carácter grandilocuente y los objetivos indeterminados de la Alemania bismarckiana. Sin duda se alegará que las diferencias que acabamos de mencionar son demasiado gruesas como para entretenerse en buscar criterios de corrección. Pero las cosas rara vez son tan simples y tan estridentes, por lo cual esta búsqueda no nos parece para nada ociosa.

En lo que sigue nos ocuparemos de textos de Goldmann y, secundariamente, de Althusser y sus discípulos. Justifiquemos rápidamente nuestra elección. En primer término, tanto Goldmann como Althusser rechazan la existencia misma de una "lógica de la explicación" universalmente válida (siquiera en términos generales), y miran con desdén la epistemología "académica" producida desde hace casi medio siglo mayoritariamente por filósofos analíticos. Para ambos, dicha epistemología es culpable de "positivismo", "empirismo" y "formalismo".

En segundo lugar, hemos elegido a estos autores porque, por un lado, Goldmann puede proporcionarnos ejemplos, a la vez, de un buen y de un mal análisis, y porque Althusser ha tratado, aun sin polemizar directamente con Goldmann, de fundamentar una concepción de la ideología radicalmente opuesta a la de éste. Así, el tratamiento conjunto de ambos autores parece adecuado, sobre todo si, como veremos, la oposición entre ellos es, desde el punto de vista que a nosotros aquí nos interesa, irrelevante.

II

Según el propio Goldman, dos veces a lo largo de su carrera él ha llevado a cabo investigaciones exitosas en el campo del análisis ideológico: una vez, al mostrar la dependencia, tanto de la filosofía de Pascal como del teatro de Racine, de una cierta variante del pensamiento jansenista y a su vez al explicar este movimiento de ideas en Francia en el siglo xvis en función de la 
crisis de la nobleza de toga ${ }^{1}$; la otra vez, al indicar la presencia de una correlación estrecha entre la novela moderna y la estructura socioeconómica del capitalismo y al explicar la evolución de esa novela por la evolución de esa sociedad.2 Comencemos por examinar la primera de estas empresas para ver si hay en ella algo irreductible a los modelos teóricos "académicos". ${ }^{3}$

Una primera lectura de algunos textos de Goldmann indudablemente puede llevar a pensar que en efecto nos encontramos con algo irreductible. No sólo porque Goldmann explicitamente se opone a tendencias emparentadas con esos modelos teóricos, sino porque parece proponer un modelo analógico-reductivo de explicación científica. Hablar de un modelo analógicoreductivo supone una doble dirección: por un lado, el modelo, en tanto que analógico, establece como momento esencial de la investigación confrontar los textos filosóficos, literarios, teológicos (para ejemplificar con los materiales que Goldmann efectivamente usa) con la base infraestructural de la sociedad a los efectos de encontrar estructuras semejantes entre uno y otro nivel, y en lo posible relaciones isomórficas entre ambos. Se diría entonces que el texto y la base social serían así, en distintos planos, la expresión de la misma realidad o que la base socioeconómica se refleja en los textos, ya que éstos guardan una dependencia estructural con respecto a las condiciones sociales que los generan. Por lo cual el modelo sería también, y a diferencia de otros que se han propuesto en las últimas dos décadas, reductivo.

Pero si esto es así difícilmente puede eludirse la conclusión de que este modelo no puede ser legitimado con los criterios canónicos de la filosofía de la ciencia. En primer lugar, porque es poco probable que haya alguna variante de éstos dispuesta a explicar $A$ por $B$ en función del isomorfismo de $A$ y $B$. En todo caso, ese isomorfismo será síntoma de una correlación efectiva, pero nunca podrá ser su criterio. $\mathrm{Y}$ además: el modelo parece presuponer un análisis inmanente del texto, no sólo en el sentido débii que consiste en llevar a cabo el análisis sin privilegiar la opinión del autor del texto sobre éste, sino también en el sentido fuerte según el cual el análisis habría de llevarse a cabo mediante un procedimiento comprensivo, esto es, mediante "la operación llamada Verstehen"."

Que Goldmann sostenga todo esto no es de extrañar, sino todo lo contrario, no bien se considera su genealogia filosófica. En efecto, este autor se remite a Lukacs y muy en especial al de Historia y conciencia de clase, ${ }^{5}$ su

1 L. Goldmann, Recherches dialectiques. Paris: Gallimard, 1955; Le Dieu Caché. Paris: Gallimard, 1955; Racine. Paris: L'Arche, 1956.

2 L. Goldmann, Pour une sociologie du roman. Paris: Gallimard, 1964.

3 Las consideraciones que aquí se hacen reelaboran los puntos de vista expuestos en J. Sasso, Sabre la sociologia de la creación literaria. Examen de las tesis de Goldmann. Montevideo: Fundación de Cultura Universitaria, 1972.

4 Tomando la expresión del conocido artículo de $T$. Abel.

3 G. Lukacs, Geschichte und Klassenbewusstsein. Berlin: Malik Verlag, 1929. 
primera obra marxista, escrita en un periodo en el que el autor conservaba, aun cuando trasplantados, múltiples rasgos de su etapa filosófica anterior, influida por Rickert, Lask y Simmel. ${ }^{6}$ Es completamente natural que Goldmann retome así puntos de vista de la verstehende Geisteswissenschaft.

Por otra parte parecería que esta apelación (explícita o no) a lo intuitivo sea también necesaria para sostener en pie el aspecto reductivo del modelo. Desde luego, no nos referimos con esto al requerimiento de pensar la totalidad, ni tampoco a la tesis de que lo que caracteriza a la ciencia social en el materialismo histórico es colocarse desde el punto de vista de esa totalidad, requerimiento y tesis que nos parecen como tales incuestionables. Lo que está urgentemente necesitado de legitimación es el modo concreto que Goldmann tiene de entender la totalidad. En efecto ella es homogénea (en la medida en que todos los planos de la realidad humana reflejan igualmente la base social) y a la vez heterogénea (desde el momento en que un plano de lo real mantiene, en última instancia, el carácter de constituyente fundamental de todo explanans); como se le ha reprochado con insistencia; esa concepción "expresiva" de la totalidad se debe a un acoplamiento, vía Lukacs, de una lógica emanantista de raíz hegeliana (que entiende que explicar un fenómeno es remitirlo a otro que sería su "verdad") a una teoría con contenido empirico (en un sentido de esto que habria que aclarar) acerca del modo de producción como base de hecho del conjunto social. Pero el peligro de esta fusión hegelo-marxista radica en que las distintas "formas de la conciencia" no son absorbidas, como en Hegel, por un concepto que alude metafóricamente al Todo, sino que se pretende que no sean otra cosa que el "reflejo", "eco", o la "espuma", esto es, simple epifenómeno, de la infraestructura social. Y difícilmente tal puede probarse siguiendo los cánones habituales de validación epistemológica.

Agréguese a esto que Goldmann, en su afán de alejarse drásticamente del "positivismo" introduce nociones que lo avecinan, por momentos, a corrientes filosóficas neorrománticas. Más aun: su afán de diferenciar al marxismo del "intelectualismo" racionalista y empirista ${ }^{7}$ lo lleva a emparentar la "filo-

6 Precisamente, esos rasgos son señalados y criticados por Lukacs en el periodo posterior de su carrera. Puede entenderse esta autocrítica como el abandono de un irracionalismo "burgués" o como servilismo ante los nuevos poderes constituidos. Ambas interpretaciones se han sostenido y muchas otras son también posibles. En todo caso es interesante comprobar que los análisis ideológicos que Lukacs ha efectuado con posterioridad siguen muy de cerca los esquemas interpretativos de Historia y conciencia de clase, texto al que no mencionan.

7 Digamos aquí que uno de los motivos de esa voluntad de diferenciación lo constituye el hecho de que ha sido norma, en la sociología de filiación positivista, una consideración atomista de la realidad social que difícilmente pueda ser tolerable para un marxista. En Las ciencias humanas y la filosofía (Buenos Aires: Galatea en Nueva Visión, 1958) Goldmann se vuelve en particular contra ese adversario. Por otra parte, es bien sabido que concepciones atomistas sobre el universo han sido, explicita o implícitamente, sostenidas por representantes o antepasados de la filosofía analítica. Sin embargo, no siempre es así. Sería 
sofía dialéctica" con las filosofías "trágicas" y a acercar; sea la noción de hipótesis a la apuesta pascaliana, sea la confianza marxista en el futuro histórico a la fe religiosa. Parecería, por lo tanto, que es vana la empresa de legitimar esas obras mediante criterios extraídos de la epistemologia "académica", lo cual, además, significa declararlas ilegitimas a la luz de dicha epistemología.

Sin embargo, esto no es así. Porque no se trata de ver qué fundamentos alega Goldmann, sino cómo pueden fundamentarse los procedimientos de investigación que efectivamente emplea. Para esto distinguiremos en su tesis sobre el jansenismo dos momentos: aquel en el que se trata de probar la pertinencia ideológica de textos filosófico-literarios y aquel en el que se intenta mostrar la base social de la ideología así circunscrita; y examinaremos cómo pueden validarse esos momentos sin recurrir a la noción de Verstehen ni a sus equivalentes.

\section{III}

La "lectura ideológica" de un texto es empresa que, como todas las de su tipo, sugiere la noción de "hermenéutica", noción atractiva pero simultáneamente indeterminada. Esa indeterminación hace que la lectura se encuentre siempre amenazada por la tentación del subjetivismo y la arbitrariedad, arbitrariedad que luego será por muchos legitimada como rasgo absolutamente insuperable de toda "hermenéutica".

Por cierto que Goldmann emplea, aun cuando ocasionalmente, la noción de "círculo hermenéutico". Y aun en forma expresa recurre a la noción de "comprensión". No obstante, su insistencia en la intima conexión entre ésta y la explicación muestra que ha advertido la existencia de un problema y al mismo tiempo testimonia la voluntad de solucionarlo siguiendo pautas objetivas.

Para empezar, examinemos con rapidez la noción ya aludida de "análisis inmanente". Como es obvio, tal análisis debe pretender, en la medida en que se inserta en la lectura ideológica de los textos, encontrar en éstos un núcleo de sentido (Goldmann lo llamará "estructura significativa") ideológicamente filiable. En los trabajos sobre el jansenismo francés del siglo xvII los textos escogidos son los fragmentos filosóficos de Pascal y las tragedias de Racine. Fijémonos en lo que se dice sobre estas últimas ya que, precisamente, las

realmente dificil llamar atomistas a las concepciones de Wittgenstein en sus Philosophical Investigations o de Quine en Word and object. Pero aun en autores en que puede hablarse de un atomismo lógico o gnoseológico, implf́cito al menos, es posible una concepción no atomista de la sociedad. Se puede haber sido partidario estricto del Círculo de viena sin desembocar por eso en lo que W. Mills llamo "sociologfa del empirismo abstracto". Es el caso de Neurath, de quien nadie ha mostrado, que sepamos, incompatibilidad alguna entre sus tesis filosóficas y sociológicas. 
obras literarias plantean problemas de lectura quizás más complejos que los escritos filosóficos.

Arriba señalamos que, en un sentido débil, un análisis es inmanente en la medida en que el texto es interpretado con independencia de las intenciones explícitas del autor y, en uno fuerte, es inmanente aquel análisis que se ejecuta aisladamente de todo lo que sea exterior al texto mismo. Ahora bien, aun cuando en Goldmann no aparecen estas necesarias distinciones resulta claro que sus procedimientos de lectura ideológica de los textos excluyen esta última posibilidad.

En efecto, este autor entiende que una pluralidad de lecturas es siempre posible si no se toman en cuenta los entornos de la obra. La pregunta no es, entonces, cómo intuir la esencia del teatro de Racine sino encontrar, en las situaciones y actitudes que se articulan en éste, estructuras que puedan ser imputables al contexto ideológico. ${ }^{8} \mathrm{El}$ sentido ideológico no se revela directamente sino mediante un análisis comparativo de lo textualmente producido con otros textos que le sirven de soporte histórico (así, las tragedias de Racine tendrán que ser cotejadas con las de Corneille, ya que aquél se inscribe en una tradición dominada por la figura de éste) o que integran esferas aparentemente lejanas, pero que están vinculadas al primero por vínculos pertinentes, por ejemplo, de contemporaneidad ( $y$ de este modo, Goldmann comparará la situación de ciertos personajes del teatro de Racine con la actitud del justo frente al mundo tal como aparece en los escritos teológicos jansenistas).

Así, es sólo usando como medio interpretativo aspectos ya conocidos de la corriente jansenista que Goldmann puede dirigirse a las tragedias de Racine buscando en ellas estructuras que pudieran ser la trasposición poética de aquellos aspectos. La articulación del texto sólo se logra recurriendo a su contexto.

Desde luego, no nos corresponde evaluar lo que de hecho Goldmann lleva a cabo, ${ }^{\circ}$ sino sólo señalar el carácter "normal" de sus procedimientos. ${ }^{10}$ Porque, desde luego, lo que en una primera instancia se obtiene es una hipótesis cuya verificación consiste en su capacidad para "cubrir" los textos. Goldmann incluso defiende sus interpretaciones apelando a lo cuantitativo: presume que ellas se acercan al ideal de ser confirmadas por el $100 \%$ def material. Con lo cual, y por lo menos implícitamente, reconoce la posibilidad

8 Cfr., Jas obras citadas en nota 1 así como "El método estructuralista-genético en la historia de la literatura", en Eco, № 61, pp. 66-86.

9 Asi, por ejemplo, no defenderfamos a Goldmann de las críticas que señalan en él una cierta rigidez interpretativa y la tendencia a encontrar "significativo" un único aspecto de los textos.

10 R. Boudon, quien en su $A$ quoi sert la notion de "structure"? (Paris: Gallimard, 1968) ha encontrado "normales" los procedimientos de Lévi-Strauss, pone a Goldmann, junto con Barthes, bajo el mismo rubro de "estructuralismo mágico". 
de ser refutado si aparecen segmentos del texto incompatibles con su lectura interpretativa. Estariamos asi frente a criterios muy clásicos en lo que respecta a la corroboración o refutación de teorías.

Por supuesto, puede darse la situación en que encontremos dos interpretaciones incompatibles que cubran igualmente los textos. La salida que Goldmann encuentra en este caso es también epistemológicamente "canónica" desde un punto de vista "académico". Por cierto que esto puede sorprender a quien tenga presente que este autor entiende que las estructuras por él descubiertas son "significativas", mientras que no lo son las de las teorias rivales sobre el tema. Esto parece constituir una apelación a la intuición; veamos, sin embargo, el caso más de cerca.

Según Le Dieu Caché, las tragedias escritas por Racine entre 1666 y 167o, se caracterizan por ser tragedias, no de la culpa y el reconocimiento (como será su Fedra de 1677), sino tragedias del rechazo. En todas ellas, por lo menos un personaje, imposibilitado de reconciliarse con el mundo, lo abandona, apelando de un modo u otro a una cierta dimensión que el mundo no puede alcanzar. Ahora bien, un rasgo propio de la ideologia jansenista es proclamar el carácter irreconciliable de la oposición del justo y el mundo y un rasgo característico de la práctica jansenista de la época es la retirada de la vida social de una serie de personas de condición que pasan a vivir "solitariamente" en Port Royal u otros lugares similares. En estas obras Racine llevaría a cabo una transposición poética de dicha ideología y dicha práctica.

Pero también se han interpretado las mismas obras como visiones de la lucha por el poder o como poetizaciones de las desdichas que produce la pasión: y esos elementos también se dan en los textos. Es frente a estas interpretaciones rivales que Goldmann sostiene que él, y no los otros, ha dado con estructuras significativas. Pero esto quiere decir: las otras teorias al respecto se colocan en un plano de abstracción no-significante, esto es, son de una generalidad excesiva, y no dan, por consiguiente, con la especificidad del texto. Porque la lucha por el poder ha sido también escenificada por Corneille, pero en él no hay jamás rechazo del mundo por parte del héroe, sino triunfo del héroe, sea sobre el mundo, sea, y aun más, sobre sí mismo, lo cual está en perfecta consonancia con el "estoicismo cristiano" característico de ciertos sectores sociales; lo mismo vale y puede repetirse para la lectura de Racine a la luz des malheurs de la passion. ${ }^{1 x}$ Que la estructura sea significativa quiere decir que los conceptos son operatorios. ${ }^{12}$

Una consecuencia importante surge de acá, y es que, cuanto más opera-

11 Para todos estos aspectos cfr., P. Bénichou, Morales du grand siècle. Paris: Gallimard, 1967 .

12 Por ejemplo, en el artfculo citado en nota 7 , Goldmann señala que muchos regimenes políticos pueden ser llamados dictaduras; pero las hay tradicionales, revolucionatias, reaccionarias, posrevolucionarias. Entre ellas hay demasiada diferencia como para que el mero concepto de dictadura posea eficacia teórica. 
torios sean los conceptos de la teoría, tanto más precisa ha de ser la hipótesis interpretativa $y$, por ende, tanto mayor habrá de ser el riesgo de refutación. La mayor significatividad de la estructura corresponde asi a un mayor grado de contrastabilidad empirica. Porque evidentemente poco hay que contrastar si, sabiendo desde siempre que en todas las obras de un autor se habla de la lucha por el poder, se declara que ese, pura y simplemente, es el sentido de sus textos; no porque se trate de una hipótesis metafísica sino, por el contrario, porque es trivial. La no trivialidad de lo significativo reside en la mayor refutabilidad de la hipótesis.

Parece entonces que, al margen de cuales sean las connotaciones filosóficas del lenguaje de Goldmann, e independientemente de la felicidad o el infortunio de sus análisis concretos, éstos pueden ser reformulados sin que entren en colisión con los principios canónicos de validación teórica.

\section{IV}

Pasemos ahora a las tesis que tratan de encontrar la base social de los textos ya ideológicamente interpretados. Es característico de muchos análisis ideológicos el empleo de mediaciones. Supuesto que el texto filosófico, literario, teológico, etc., deba "en última instancia" determinarse por la base material de la sociedad, se entiende necesaria la búsqueda de estructuras intermedias entre el texto:y la base. La matriz ideológica de la que el texto es una variante es ya un elemento mediador, si bien no será el único.

En la investigación concreta que examinamos, los niveles mediadores están dispuestos de la siguiente manera: una vez encontrada la ideologia jansenista como núcleo que engloba tanto la filosofía de Pascal como el teatro de Racine, se trata de conectarla con el grupo o los grupos sociales pertinentes: en el caso, con la nobleza de toga, esto es, con la burocracia hereditaria de origen burgués, pero situada ya fuera del proceso productivo, que ha sido el soporte tradicional del estado monárquico y que ahora es dejada de lado por éste, el que sé encuentra en el ápice de su poder y prefiere buscar servidores sin tradiciones ni opiniones propias. Una vez establecida la difusión del jansenismo en Francia en el siglo xvi como producto de la crisis de tal estamerito, se procederá a enmarcar ésta en el cuadro general de su tiempo, de sus conflictos sociales, de las relaciones entre los diversos grupos y el estado.

En este camino podemos emplear una serie de recursos que nos permitan verificar si existen o no, en los hechos, las conexiones mencionadas. Uno de ellos es mostrar cómo el personal jansenista se recluta principalmente entre los medios togados; otro consiste en indicar que los dos momentos de crecimiento de los "discípulos de San Agustin" suceden a continuación de sendas derrotas de la nobleza de toga en su lucha contra el poder monárquico; un 
tercero es señalar que ninguna otra corriente ideológica de la época posee composición social similar; un cuarto consiste en indicar como significativo que el jansenismo haya podido resistir la persecución casi hasta el fin del reinado de Luis XIV, cuando el calvinismo, con su medio millón de adeptos (cifra imponente en relación al contingente numérico de los "amigos de Port Royal") no pudo hacerlo, lo que a su vez se explica por la resistencia pasiva de los tribunales de justicia encargados de ejecutar las medidas antijansenistas, los cuales estaban en manos de la nobleza togada. No corresponde entrar en el detalle: lo que sí parece manifiesto es que ninguno de esos recursos es discontinuo con los procedimientos inductivos (dicha sea esta palabra sin ninguna pretensión teórica) más habituales.

Dichos procedimientos se ven acompañados (como siempre sucede en estos casos) de otros principios auxiliares que valen como apoyos heurísticos. Por ejemplo, el concepto de conciencia posible del grupo social, esto es, el modo de sentir, interpretar y valorar la realidad con mayor coherencia respecto de la situación objetiva del grupo como tal. La conciencia posible, desde luego, no equivale a la conciencia que de hecho se manifiesta en tales o cuales integrantes del grupo, sino como aquella forma a la que tiende el grupo social. Se preguntará quizás con qué derecho puede ser reconstruida. La respuesta es: a partir de la conciencia empíricamente registrable, del testimonio de los adversarios de la ideología, en la medida en que no es mera propaganda (así, las "proposiciones" que la Iglesia cree encontrar en el jansenismo, aunque éste se rehusa a admitirlas como suyas), o por analogia con otras situaciones ideológicas. Se cuestionará quizás que no hay verificación directa de tal conciencia posible. Lo cual es muy cierto, pero sólo constituye argumento decisivo en contra para una concepción demasiado estrecha de la ciencia.

Una forma de validar la construcción hipotética que es la conciencia posible de un grupo dado seria mostrar que sin dicha construcción la teoría no puede ser articulada adecuadamente, y que los otros enunciados de la misma sí pueden ser confirmados empíricamente ${ }^{13}$; otra posibilidad especialmente fuerte (si bien, por la naturaleza de los trabajos en ciencias sociales, poco común) sería que la conciencia posible construida hipotéticamente adquiriera relevancia predictiva. En el caso, habría de tratarse de la capacidad para dar lugar a retrodicciones. Goldmann sostiene, precisamente, que así ha sido: en efecto, la corriente mayoritaria del jansenismo le parecía demasiado lejana de la coherencia sin compromisos de Pascal y Racine; extremando ciertos rasgos de ella construyó la conciencia posible de un jansenismo

13 El locus classicus es R. Carnap, "The Methodological Character of Theoretical Concepts", en Feigl-Scriven (comps.), Minnesota Studies in the Philosophy of Science, I: The Foundations of Science and the Concepts of Psychology and Psychoanalysis. Minneapolis: Minnesota University Press, 1964 , pp. 38-76. 
"trágico": pues bien, la investigación documental mostró luego que efectivamente existía una variante extremista del jansenismo, coincidente en líneas generales con la conciencia posible reconstruida a partir del jansenismo habitual y (en el otro extremo) de los textos de los autores mencionados.

El otro recurso heurístico consiste en introducir la noción de coherencia funcional (o sus variantes más drásticas: "homología", "isomorfismo", de las que por ahora prescindiremos) del siguiente modo: el jansenismo insiste en el carácter objetivamente escindido de la condición humana. Así el hombre es un junco, pero un junco pensante; así el "caso de conciencia" más grave para el jansenismo se da al encontrarse frente a exigencias contradictorias: proclamar su credo y al mismo tiempo permanecer fiel a la Iglesia que condena dicho credo. Pues bien, la nobleza togada es, precisamente, la clase social que se encuentra, en el cuadro de la época, en esa situación de desgarramiento. Burguesa de origen, pero ennoblecida y habiendo abandonado ya su lugar en el proceso productivo. Noble de condición, pero desdeñada por la nobleza "de espada". y excluida como tal de la corte. Ligada desde los orígenes al poder monárquico y a su expansión, pero socavada por ese mismo poder que quiere verse libre de toda traba. Producto del estado opuesto al estado, el togado no será capaz ni de llevar su oposición hasta extremos revolucionarios, ni pura y simplemente transformarse en dócil funcionario de nuevo cuño. ${ }^{14}$ Sólo le resta, si es coherente con su situación, vivir la contradicción y rechazar tajantemente el "curso del mundo". Desde luego, esta coherencia es excepcional: pero porque toda coherencia radical lo es. $\mathrm{Y}$ esta tesis psicológica trivial impide que pueda usarse como contra-argumento que la mayor parte de los togados no sea jansenista militante. Mientras la coherencia funcional sirva de hilo conductor de la investigación, y no pretenda ser algo que se "comprende" intuitivamente, ni una "verdad" independiente del conjunto de los hechos comprobables, para nada nos alejamos de los modelos epistemológicos canónicos.

Podría alegarse, en contra de nuestro intento de mostrar que nada hay de inhabitual o irreductible en la metodología de Goldmann, que éste no se limita a establecer una conexión de hecho entre ideologia y grupo social, sino que proclama una vinculación de derecho entre ambos, al hablar de "visión del mundo de la burguesía", de la aristocracia o de la nobleza de toga. ${ }^{15}$ ¿No habrá aqứ un esencialismo sólo justificable mediante la intuición o, lo que es lo mismo, canónicamente injustificable?

14 Desde luego nadie pretenderá que este enunciado sea determinista. Habrá "tránsfugas" que pasarán a integrar la nueva burocracia, lo que no altera la verdad global de lo dicho. (En cambio, la nobleza cortesana no estará integrada por tránsfugas, ya que es producto de la metamorfosis en bloque de la alta nobleza terrateniente, que puede así sobrevivir bajo el absolutismo monárquico.)

15 Muy notorio hacia el final de Las ciencias humanas y la filosofia, este rasgo es 
Desde luego, puede ser que en la representación que Goldmann se hace de las cosas sí haya tal esencialismo (veremos luego que asi es). Pero lo que aquí interesa es si resulta forzoso el esencialismo a la luz de la investigación concreta de Goldmann. $\mathrm{Y}$ nos parece que la vinculación de derecho entre visión del mundo y clase social no es una realidad extra-empírica que haya que "comprender" intuitivamente (o rechazar como sinsentido), sino una tesis intrateórica acerca del tipo de relación existente entre la ideología y cierto grupo social.

El problema, rápidamente planteado, es éste: junto a los togados, hay jansenistas de otra extracción social: particularmente importantes son los miembros de la alta nobleza que se hacen jansenistas luego de fracasar polfticamente. Sostener que hay una diferencia cualitativa entre estos últimos y los togados significa sostener que la adhesión de los aristócratas es meramente periférica y circunstancial ya que la nobleza como tal tiene otras opciones que, en definitiva, serán las adoptadas. Cuando se dice que la fracción de los togados "se expresa" específicamente en el jansenismo, se quiere indicar que para el conjunto de este estamento no existe otra visión del mundo que articule su experiencia, ni otra forma, fuera de la mera pasividad, de oponerse a los poderes constituidos. Así Goldmann dirá que la oposición no revolucionaria implicada por el jansenismo "refleja" la situación objetiva y contradictoria del grupo social. Cabe plantearse cómo se podrá verificar esa especificidad. Un camino posible ${ }^{16}$ es mostrar cómo el jansenismo cuestiona el universo de valores de la aristocracia terrateniente, cómo rebaja o ridiculiza la "grandeza" del noble, cómo encuentra tras ella motivos egoístas o vanos, con qué aspereza rechaza el aristocrático "estoicismo cristiano". Otro puede ser probar documentalmente cómo se eclipsa el jansenismo aristocrático tras unos años de existencia: precisamente, cuando llega a su apogeo el absolutismo centrado en la vida de corte. En ningún caso, al fundamentar la peculiaridad de la relación entre jansenismo y toga, nos apartamos de procedimientos canónicos de validación.

\section{V}

Podemos ahora intentar preguntarnos por el tipo de teoría que es la de Goldmann. Se ha distinguido 17 una serie de oposiciones pertinentes para caracterizar los nexos explicativos que constituyen las teorfas sociológicas: las relaciones establecidas pueden ser reversibles $(X \rightarrow Y . Y \rightarrow X)$ o irreversibles, deterministas o estadisticas, secuenciales o coextensivas, suficientes $(X \rightarrow Y$, permanente en Goldmann, pero no es característico de todos los intérpretes marxistas. Un punto de vista contrario se encuentra en $\boldsymbol{H}$. Lefebvre.

16 Seguido éste por Bénichou; el segundo, por el propio Goldmann.

17 Cfr. H. Zetterberg, "Consideraciones sobre la construcción y verificación de la teoria en sociologia", tomado de Quademi di Sociologia, volumen XII (1963). 
independientemente de cualquier otro hecho) o contingentes $(X \rightarrow Y$, si además $Z$ ), necesarias (sólo si $X, Y$ ) o sustituibles $(X \rightarrow Y$ pero también $Z \rightarrow Y$ ). Sea $X$ la crisis de la nobleza de toga e $Y$ el jansenismo de Port Royal. De inmediato se advierte que la tesis de Goldmann es irreversible, estadistica, secuencial. También es una relación necesaria, ya que esa corriente religiosa no se hubiera difundido con esas características sin la presencia militante de togados en ella (hubiera sido, en todo caso, un simple fenómeno intraeclesiástico, como lo fue en su país de origen) y contingente (o sea, la presencia de los togados es necesaria pero no suficiente).

De la contingencia se infiere que $X$ ha producido $Y$ sólo por medio de una constelación $C$ de elementos secundarios. Estos elementos pueden ser muchos y de muy diversas clases: así lo son las hipótesis psicológicas (que por ser de experiencia cotidiana no están siquiera formuladas) acerca de las respuestas a las frustraciones; la hipótesis, tomada de Piaget, sobre la existencia de un cierto núcleo de individuos que tratan de expresar su situación en todos los planos con un máximo de coherencia; las consideraciones sobre el entorno histórico; la existencia de tradiciones filosóficas, religiosas y aun teológicas con sy modo propio de operar, etc.

Si al observar este conjunto de características, y en especial la última, nos preguntamos qué modelo epistemológico puede adecuarse a la teoría, encontraremos natural interpretarla como un caso de explicación históricogenética. ${ }^{18}$ Hay explicación genética cuando la relación explicativa exhibe al explanandum como miembro final de una cadena de acontecimientos. Supongamos que un automóvil se detiene y se nos da como explicación ("pragmática") que hay un agujero en el cárter de aceite. Estos extremos de la cadena explicativa pueden aproximarse introduciendo diversas mediaciones: el automóvil se ha detenido porque no funciona el motor; el motor no funciona porque ha cesado el movimiento de los émbolos del cilindro; pero a su vez éstos no se mueven porque se han dilatado por falta de lubricación, y esto sucede porque, por haber un agujero en el cárter de aceite, éste no llega al cilindro.

Obviamente, para que esta explicación sea satisfactoria, estas condiciones antecedentes singulares deben completarse con leyes apropiadas. Si asi se hace obtenemos la siguiente cadena:

$$
S_{1} \rightarrow S_{2} \rightarrow S_{s} \ldots S_{n-1} \rightarrow S_{n}
$$

donde $S$ es la constelación de sucesos pertinentes en un momento dado del proceso (o mejor, el conjunto de enunciados que describe dicha constelación)

18 Lo que sigue retoma la exposición de W. Stegmüller, Probleme und Resultate der Wissenschaftstheorie und Analytischen Philosophie, I: Wissenschaftliche Erklärung und Begrïndung. Berlin-Heidelberg-Nueva York: Springer Verlag, 1969, pp. 352-360. 
y las flechas representan las conexiones causales (esto es: según leyes generales).

De ser esto así, nos encontramos con una explicación sistemático-genética. En ella el proceso va de un estado inicial de cosas $S_{1}$ a otro $S_{n}$ a través de una serie de estados intermedios, cada uno de los cuales es suficiente como elemento de transición, supuestas las leyes aludidas. Es obvio que las explicaciones históricas no se caracterizan por este encadenamiento fuerte, sino por otro más débil cuyo esquema podría ser el siguiente:

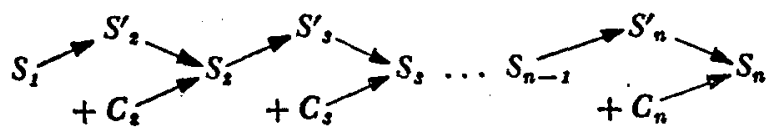

$S_{2}^{\prime} \ldots S_{n}^{\prime}$ representarían las consecuencias inferibies del estado de cosas anterior, mientras que $C_{2} \ldots C_{n}$ simbolizan la información adicional que en las explicaciones de esta naturaleza (histórico-genética) debe ser proporcio nada para legitimar $S_{2} \ldots S_{n}$. No basta entonces, para inferir $S_{2}$ de $S_{1}$ conocer $S_{1}$ y ciertas leyes generales, sino que siempre será necesaria la incorporación de información residual.

Si representamos por $S_{1}$ la consolidación del estado absolutista en Francia desde 1600 , por $S_{\varepsilon}$ la creación de una nueva burocrácia sin tradiciones propias, por $S_{s}$ el descontento de la nobleza de toga frente al estado de cosas reinante, por $S_{4}$ la conversión al jansenismo o la simpatía por él, por $S_{5}$ la variante extremista del jansenismo, por $S_{6}$ la visión del mundo de la filosoffa de Pascal o la inserta en las tragedias de Racine, podemos entonces esquematizar la situación así:

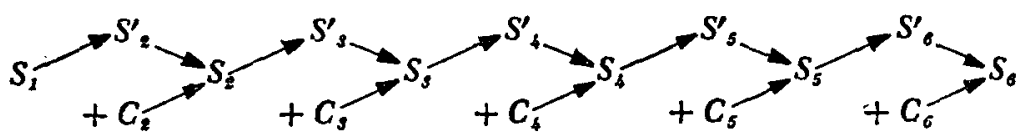

En $\mathrm{C}_{2}$ debe encontrarse información sobre el equilibrio de clases en el siglo xvir francés y sobre sus antecedentes, que incluyen el surgimiento de la nobleza de toga y su transformación en una casta hereditaria, así como la historia de la corona francesa, con sus conflictos con los parlamentos y las cortes soberanas, su política fiscal y administrativa, etc. En $C_{s}$ encontramos información sobre el desplazamiento de los togados, su dependencia financiera de la corona y su falta de bases materiales propias, sobre el comportamiento fluctuante de los togados en la guerra civil de la Fronda y sucesos similares. En $C_{4}$ hay que acumular enunciados de muy heterogénea naturaleza, algunos sobre la nobleza togada, otros sobre las doctrinas teológicas cristianas y sus vicisitudes históricas. 
Algunas consecuencias de esta situación son patentes: así el claro desvío que este modelo supone respecto del "paradigma ideal" de explicación nomológico-deductiva, la asimetría que se establece entre explicación y predicción $y$, por consiguiente, la imposibilidad (a diferencia del caso de las explicaciones sistemático-genéticas) de eludir en la teoría los pasos intermedios del proceso. Asimismo los enunciados $C_{z} \ldots C_{n}$ no pueden ser meramente supuestos, sino que son terreno pasible de confirmación o refutación. De este modo la explicación histórico-genética sirve de canon a investigaciones futuras que han de ir completando el explanans, tarea en principio inacabable y que determina que este modelo sea un caso de lo que se denomina bosquejo de explicación. ${ }^{19}$

Desde luego, nada más fácil para un partidario del Verstehen que declarar esta incompletitud como índice de una radical heterogeneidad entre las disciplinas fisico-naturales y las sociales, y que en éstas no hay "ciencia" sino "conciencia"; que, como la historia es la obra del hombre, ella pide un modelo sui generis de teoría, fundado en la autognosis. Sin embargo, contra esto puede señalarse que: 1) no es cierto que haya una correspondencia biunivoca entre explicación histórico-genética y objetos socioculturales por una parte, y modelo nomológico-deductivo y objetos físiconaturales por la otra; así, no sólo encontramos explicaciones no-históricas en sectores de ciencias socioculturales, sino también explicaciones histórico-genéticas de la naturaleza, como sucede en la teoría de la evolución de las especies; 2) puede establecerse una continuidad entre ambos tipos de explicación, que excluya la dicotomía tajante del dualismo. Es así que a partir del paradigma ideal se ha podido señalar toda una gradación que pasa por las explicaciones incompletas, inexactas, rudimentarias, parciales, esquemáticas. En todo caso, este panorama es demasiado rico para subsumirlo en la alternativa rígida ciencia/conciencia; 3) en el caso concreto de la teoría de las ideologías en el marco del materialismo histórico, se plantea una dificultad especial, similar a la que se produce cuando se intenta legitimar mediante el Verstehen la teoría psicoanalítica del inconsciente. Porque, ¿con qué derecho podemos hablar de autoconocimiento, y cómo se compadece éste con la universalidad de la ideología? ¿En qué queda la autognosis si lo que se descubre por medio de ella es el hiato entre el saber teórico y la conciencia espontánea y aun el carácter ilusorio de ésta? Resuélvase como se quiera esta dificultad, ${ }^{20}$ parecería que esta incompatibilidad entre la transparencia del modelo gnoseológico y la opacidad de la conciencia espontánea según el materialismo

19 C. G. Hempel, "La función de las leyes generales en historia", tomado de FeiglSellars (comps.), Readings in Philosophical Analysis. Nueva York: Appleton-Century-Crofts, 1949 .

20 Una forma de resolverla es adoptar un historicismo extremo, que entienda que las etapas posteriores de la sociedad pueden "ver" la "verdad" de las anteriores. Desde luego. esta forma de resolver el problema da lugar a otros más graves. 
histórico es lo que está en la base del abandono lukacsiano de las posiciónes de Historia y conciencia de clase. Más razonable es entonces interpretar el análisis ideológico a la luz de la lógica canónica de la explicación científica.

\section{VI}

La adopción de un modelo epistemológico de corte hempeliano para el análisis ideológico puede dar lugar a una serie de objeciones, así como también pueden cuestionarse puntos de vista carnapianos y popperianos que arriba también han sido manejados. Desearíamos aquí, no obstante, indicar lo siguiente: no se trata de defender la aplicación concreta de ese modelo ni de esos puntos de vista sino, con más modestia, de mostrar la posibilidad de dicha aplicación. Porque no nos sentiríamos en absoluto refutados si la grey de los epistemólogos "académicos" optara por abandonar radicalmente la lógica hempeliana de la explicación y sustituirla por otra metateoría. La adopción del modelo de explicación histórico-genético no nos parece el término del análisis, sino su comienzo, o si se prefiere, una adscripción provisoria. Alguien podrá encontrar un modelo mejor que dé cuenta de los mismos hechos de teoría y aun de otros. Y bien, si esto es así, habremos de cualquier modo integrado el análisis ideológico en el marco de lo plenamente debatible a la luz de la filosofía canónica de la ciencia. Lo que nos interesaba era eliminar la apariencia de que dichos análisis se encuentran esencialmente unidos a interpretaciones intuicionistas del quehacer teórico. Entonces, si se abandona la lógica hempeliana de la explicación por otro modelo epistemológico todo lo que pudo interpretarse a la luz de ese modelo tendrá también que poder ser interpretado en el marco del nuevo. El análisis ideológico padecerá entonces un destino común y sea cual fuere la metateoria que se adopte en general, tendrá que ser tomado en cuenta al legitimarse el cambio epistemológico, no pudiendo ser dejado de lado como una excentricidad inasimilable.

Sobre dos consecuencias de esto importa ahora llamar la atención. La primera de ellas es que es posible considerar la teoria de Goldmann que acabamos de examinar sin introducir un modelo analógico-reductivo de interpretación. Porque si puede pensarse tal teoría como un caso de explicación histórico-genética, si los nexos explicativos que ella establece son necesarios pero no suficientes, entonces no habrá reduccionismo alguno. $Y$ no sólo porque Goldmann diga en más de una ocasión que hay que respetar la relativa autonomía de los distintos planos de la realidad social, sino porque tal reducción se ha vuelto lógicamente imposible.

$\mathrm{Y}$ tampoco el modelo será analógico. En nuestra "reconstrucción racional" de la teoría de Goldmann, la coherencia funcional que se expresa en la afinidad de situaciones vale sólo como apoyo heurístico y no puede sus- 
tituir las instancias normales de confirmación. La semejanza, analogía o isomorfismo, no es criterio, sino síntoma de un nexo que debe probarse examinando las estructuras mediadoras. Si la analogia valiera como criterio esto no sería necesario: al haberla, resultaría ocioso considerar la teoria como una hipótesis confirmable o refutable por los datos que puedan obtenerse sobre el movimiento real de esos planos mediadores. ${ }^{21}$

Pero en cambio obtenemos un criterio para decidir entre usos legitimos e ilegítimos de la analogía. Desde luego será de antemano ilegítimo todo uso de ésta que no pretenda mantenerse en el plano de lo heurístico y que quiera sustituirse a las instancias "normales". La verdad o la falsedad de los enunciados teóricos habrá de establecerse por procedimientos del todo independientes de las conexiones puramente sugestivas que los puedan haber inspirado. El valor de la analogía dependerá de algo externo a ella: su capacidad de propiciar una expectativa fundada de teoria confirmable. A esa discriminación de usos legítimos e ilegítimos de la analogía, que de aplicarse consecuentemente obligaría al rechazo o a la precisión y reelaboración de tantos esbozos (por lo general ensayísticos) de análisis ideológico, debe unirse otra: la que, en función de la categoría de mediación, permite apreciar un rasgo fundamental de todo "buen" análisis.

En efecto: si se admite la pertinencia del modelo histórico-genético puede precisarse la función de dicha categoria. Como es sabido, ella ha dado lugar a debates. ${ }^{22}$ Se la ha criticado por no ser otra cosa que el lugar de resolución ilusoria de un problema ilusorio: el de incorporar al discurso teórico los instrumentos conceptuales capaces de permitir el pasaje continuo de la base material a la superestructura ideológica.

Pero es claro que tal no es el papel que desempeñan los niveles mediadores en una explicación histórico-genética, ya que ninguno de ellos permite, ni aun con ayuda de generalizaciones, pasar al otro sin información adicional, lo que impide que cada nivel mediador sea el "reflejo" en otro plano de una "misma" verdad que se desplegaria desde la infraestructura sócial hasta las alturas ideológicas. Así entendida, la noción pierde todo su misterio y se convierte en un instrumento capaz de volver operatorio el análisis, al posibilitar, paso a paso, instancias concretas de confirmación empirica. ${ }^{23}$

21 Como tal hipótesis presenta siempre Goldmann su teoría.

22 En particular, Althusser y sus discípulos son críticos acerbos de su uso.

23 Quizás Sartre (que parte también del Lukacs hegelo-marxista, pero que parece mucho más fiel al modelo inicial y menos "reformulable") merezca los reproches de Althusser, ya que parece creer en el "pasaje continuo" al rechazar como abstracción innecesaria el concepto de personalidad básica de Kardiner y Linton (cfr. "Question de Méthode", en Critique de la Raison Dialectique. Paris: Gallimard, 1960). En cambio, y al margen de lo que valga la teorfa de la personalidad básica, ha podido ser integrada con naturalidad en una perspectiva goldmanniana; cfr. G. Mury, "Sociologie du Public Littéraire: le Concept de PeTsonnalité de Base et la Conrvergence des Procédures de Recherche", en R. Escarpit (comp.), 
Hay sin embargo más: desde el momento en que la explicación genética es histórica y no sistemática, las mediaciones no pueden ser suprimidas. De aquí se desprende una importante consecuencia: si encontramos un análisis que pretende remitir directamente el texto filosófico, literario, teológico, etc., a la base material de la sociedad, habremos de considerarlo una empresa ilegítima. Es frecuente encontrar autores que practican, sin clara conciencia de la diferencia, tanto un análisis con mediaciones como sin ellas. Pero este segundo caso es inasimilable a las pautas canónicas de explicación científica, no habiendo continuidad entre ambos tipos de tarea. De ningún modo una interpretación directa del texto por la base social puede considerarse una forma abreviada del análisis ideológico a través de niveles mediadores. Dicho de otra forma, no es cuestión de economía teórica.

Si la existencia de mediaciones es condición necesaria (aun cuando desde luego no suficiente) para un buen análisis, será posible entonces, contra la amalgama practicada tanto por Goldmann como por sus críticos más encarnizados, aceptar la corrección epistemológica de su teoría sobre el jansenismo y rechazar en cambio su interpretación sociológica de la novela. El núcleo central de ésta se encuentra en la explicación de la estructura narrativa clásica por la estructura del intercambio en la economía liberal. El concepto de estructura narrativa clásica es tomado por Goldmann de una obra premarxista de Lukacs ${ }^{24}$ y consiste en interpretar la novela con "héroe problemático" (que sería el paradigma clásico del género) a la luz de los problemas de la sociedad individualista de libre mercado. La novela sería la trasposición imaginaria de ciertas características esenciales de esa sociedad. Entre ambas estructuras, piensa Goldmann, hay una "homologia rigurosa" que se confirmaría por la evolución misma del género: a medida que la sociedad occidental tiende al capitalismo monopolista asistimos a una transformación paralela de la novela, caracterizada por la disolución progresiva del "personaje" hasta su desaparición final. El nouveau roman, que se presenta al término de esta evolución, nos describe un universo autónomo de objetos; asimismo, en el capitalismo contemporáneo los grandes monopolios y su manejo impersonal del mercado borran por completo las últimas características remanentes del individualismo competitivo.

Sería demasiado extenso un análisis de todo esto, siquiera por la enorme riqueza del material empírico al que se pretende interpretar; digamos que autores como Badiou ${ }^{25}$ se han apoyado en esta "admirable simplicidad" para demoler todo el edificio teórico así construido. Porque obviamente surgen

Le Littéraire et le Social. Eléments pour une sociologie de la Littérature. Paris: Flammarion, 1970 .

24 G. Lukacs, Die Theorie des Romans. Berlin: Cassirer, 1928.

25 A. Badiou, "Le (re)commencement du materialisme dialectique", en Critique (1967), pp. $43^{8-467}$. 
aquí diversos cuestionamientos posibles: 1) ¿No será que el material se pliega a los concéptos genéricos porque son genéricos en demasfa? Cabe la sospecha de estar actuando en el plano de la abstracción no significante y elaborando, en el-sentido arriba aludido, conceptos no-operatorios; 2) la delimitación de lo esencial en todo el género novelesco, ¿no se hace mediante una decisión arbitraria que exige como fundamento una intuición no controlable?; 3) ¿De qué manera piensa Goldmann comprobar su teorfa? Porque si no hay mediación alguna, ni ideológica ni social, no habrá tampoco confirmación posible de enunciado alguno. Quedan tres soluciones: o los textos literarios se infieren directamente de la estructura económica (lo que sería por lo menos insólito), o planteamos una tesis psicológica sobre el inconsciente de los individuos, tratando de probar la existencia de trasposiciones imaginarias latentes de estructuras económicas a nivel de la creación de obras literarias (y esta tesis es igualmente insólita) o, cosa más probable, la "teoría" no es otra cosa que la comprobación de una analogía u homologia entre literatura y economía, comprobación que se agota en sí misma y a nada conduce.

Se planteará cómo es posible que Goldmann haya efectuado una construcción tan "a prueba de contrapruebas", cuando su teoria sobre el jansenismo presentaba tan diversos caracteres. Una respuesta posible es que, llevado por un marco conceptual heredado de los teóricos de la operación Verstehen, no valoró en forma adecuada la estructura epistemológica de su propia investigación. Así, nos parece que, por más que Goldmann hable de confirmación o refutación de hipótesis, no le concede a esto tanta importancia como a la coherencia funcional entre texto e infraestructura; o sea que para él lo que hemos valorado como recurso heurístico parece esencial y no accesorio, no es sólo sintoma de la corrección teórica sino también criterio. Pero esto sólo puede conducir al error. De ahí que, al comienzo, hayamos dicho que una importación consciente del campo problemático de la epistemologia "académica" podría ser provechosa en la práctica del análisis ideológico.

\section{VII}

Consideremos ahora, muy brevemente, el caso de Althusser.

Althusser rechaza por entero la concepción "expresiva" de la totalidad que Goldmann representaría con particular claridad. En su lugar propone una noción "estructural" de causalidad que habría de diferenciarse por completo tanto de la expresiva como de la "causalidad mecánica lineal". De algún modo (y la precisión de este modo es bastante trabajosa, a juzgar por los escritos: de Althusser y los suyos) la base material de la sociedad determina "en última instancia" los otros planos de la misma, pero sin que haya planos que reflejen, expresen $o$ traspongan otros. ${ }^{28}$

26 Entre tantos textos, cfr., sobre todo "Contradicción y sobredeterminación", en La 
Es cierto que, de acuerdo con lo que acabamos de ver, sea cual fuere la concepción goldmanniana de la totalidad y de lo que con ella se cree hacer, lo que Goldmann efectivamente hace puede ser legitimable (en los análisis con estructuras mediadoras) de acuerdo con un modelo que nada tiene de analógico-reductivo. Pero, al igual que Goldmann, Althusser tiende a fijarse mucho más en las ideas explícitas que en los procedimientos implícitos. Desde luego, esto no quiere decir que carezca de importancia para el análisis concreto la concepción de la totalidad subyacente; es muy probable que dos concepciones de la totalidad social radicalmente distintas orienten la investigación por caminos diversos. No obstante ambos caminos, al margen de la verdad o falsedad de sus resultados, bien podrian ser validables, como tales, por un mismo modelo explicativo. Dicho de otro modo: dos investigadores, $A$ y $B$, poseen distintas concepciones de la totalidad social. Esa discrepancia orienta sus trabajos por caminos diferentes. Si su tema es el mismo, puede ser que surja, de esta divergencia, una incompatibilidad empírica entre la teoría de $A$ y la de $B$. Pero esa incompatibilidad puede deberse con exclusividad a la hipótesis sobre la totalidad que se ha adoptado como punto de partida, y no afectar para nada el hecho de que tanto $A$ como $B$ hayan seguido, por ejemplo, un modelo de explicación histórico-genético. De esto último solamente tratamos aqui.

A primera vista podría presumirse, siendo tan recurrentes en Althusser los términos "ciencia" y "epistemologfa", una cierta consideración por la filosofia "académica" de la ciencia. Nada más ajeno que esto, sin embargo, a su punto de vista. Porque una caracteristica notoria de esa filosofia es el intento de proponer criterios genéricos de cientificidad. Pero justamente eso es lo que Althusser niega rotundamente. A su juicio, la tradición "académica" prolonga las tesis "empiristas-positivistas" y éstas son directas herederas de la problemática clásica que pregunta por las garantías del sujeto en tanto que aprehende el objeto. Althusser busca evitar esa problemática estableciendo que el proceso de validación del conocimiento sucede en el interior de la práctica que lo produce, es decir, negándose a admitir que haya otra corroboración de los enunciados científicos que aquella que se da en el interior mismo de la práctica tebrica ${ }^{27}$; cada disciplina científica en cada momento dado (o sea, en los hechos, cada comunidad cientffica) ha de establecer los criterios para juzgar la calidad de sus creaciones. La validez de los procedimientos no es algo que pueda decidirse mediante los parásnetros de una "Iógica de la ciencia" sino que es inmanente al propio "dis-

revolución teórica de Marx. México: Siglo XXI, 1968; así como E. Balibar, "Sobre los conceptos fundamentales del materialismo histórico", en Para leer El Capital. México: Siglo XXI, 1969 .

27 Lo que aquil se alude rápidamente ha sido tema de J. Sasso en La fundamentación de la ciencia según Althusser. Montevideo: Fundación de Cultura Universitaria, 1971. 
curso teórico". Más aún: la epistemología "académica" se encuentra viciada por pretender extender a otros campos criterios que quizás puedan, a lo sumo, valer para la física. Porque en las ciencias físicas "el criterio de su teoría son sus experiencias, las que constituyen la forma de su práctica teórica", ${ }^{28}$ sin duda: pero eso es así porque el discurso de la física se da a sí mismo esas experiencias como criterio de su validez. Es muy posible una práctica cientifica que eluda todo tipo de confirmación empírica de esta índole. Cuando Althusser incursiona por la psicología por ejemplo, lo hace para afirmar la verdad del psicoanálisis en contra de la verdad de la psicología experimental, la cual "reposa sobre un equivoco", ya que ha extendido ilegitimamente la racionalidad propia de las ciencias físicas. Y no porque se esté objetando el traslado mecanicista de técnicas de la física a la psicología, sino porque hay "continentes" irreductibles entre sí: Galileo, Marx, Freud, habrían "abierto" esos distintos "continentes". ${ }^{29}$ Henos aquí, con algunas variantes, en el terreno de lo que en un tiempo Husserl denominó "ontologias regionales".

Si esto es así entonces, desde el punto de vista de la epistemologia "académica" la respuesta es rápida: ese inmanentismo no permite juzgar la diferencia entre una teoría científica auténtica y un mito, una metafísica o una ideologia; menos aun podrá sobre estas bases fundamentarse un análisis ideológico; todavía menos podrán obtenerse pautas para diferenciar un buen análisis de otro que no lo es.

Es cosa entonces de preguntarse: ¿practicará Althusser el análisis ideológico mediante criterios de racionalidad radicalmente nuevos, tanto, que no puedan ser canónicamente legitimados? ¿Implicarán, sea la causalidad estructural, sea el inmanentismo epistemológico, una perspectiva excluyente del modelo histórico-genético que caracteriza objetivamente los buenos análisis de Goldmann, supuestamente basados en una causalidad expresiva? Pues bien, no. Ciertamente, apenas podemos fundar esta negación en textos del propio Althusser ya que, cuando éste habla de ideologia, habla de la ideologia en general, sin llevar a cabo análisis concretos..$^{30}$ Pero si examinamos los trabajos pertenecientes a quienes se remiten a su obra, como Poulantzas ${ }^{31}$ o Macherey, ${ }^{32}$ no encontraremos procedimientos radicalmente nuevos de legitimación de una lectura ideológica de textos ni de una imputación social de ideologías.

28 L. Althusser-E. Balibar, Para leer El Capital, p. 66.

29 L. Althusser, Lénine et la Philosophie. Paris: Maspero, 1968, pp. 24 s.

30 Porque por tal no puede entenderse el análisis que se encuentra hacia el final de su Ideologia y aparatos ideológicos de estado. Buenos Aires: Nueva Visión, 1974, pp. 72-80. Tal análisis de la "ideología religiosa cristiana" sólo pretende, a través de ciertos aspectos de un caso especial, mostrar ciertos rasgos de la ideologia en general.

31 N. Poulantzas, Clases sociales y poder politico en el estado capitalista. Buenos Aires: Siglo XXI, 1969 .

32 P. Macherey, Pour une théorie de la production littéraire. Paris: Maspero, 196̆n. 
El caso de Macherey tiene interés especial, ya que, por ocuparse de textos literarios y por hacerlo desde una perspectiva de la totalidad que contradice la de Goldmann, puede ser contrastado con los procedimientos de éste. Ciertamente Macherey, a diferencia de Goldmann, no busca en la obra una "estructura significativa" que exprese la realidad social, a través de la ideología, con un máximo de coherencia, sino aspectos, no necesariamente dotados de cohesión, donde se registra el punto de vista del autor y desde donde puede ser remitido a una ideología. Pero estas diferencias con Goldmann tienen que ver con una distinta hipótesis previa sobre el modo de inserción de lo ideológico en lo literario y no suponen un "criterio de verdad" especifico. Igualmente, cuando Macherey nos muestra a Tolstoi como escritor campesino, su modo de ligar la obra y la ideología tolstoianas con la base social, si bien sigue pautas más flexibles (o más confusas, diría quizás un contradictor) que Goldmann en su teoría sobre el jansenismo, no por ello lleva a cabo un análisis cuya marcha sea irreductible a un modelo explicativo histórico-genético, sino que sigue siendo perfectamente adaptable a él.

La conclusión que parece imponerse es que el análisis ideológico, empresa en un cierto sentido profundamente clásica, puede validarse mediante modelos epistemológicos canónicos, sin perjuicio de que quienes lo cultiven posean concepciones divergentes sobre la ideología y sobre su articulación en la totalidad social.

\section{VIII}

Se podría quizás objetar a la perspectiva que acabamos de establecer que ella se mantiene sólo porque en ningún momento hemos cuestionado la tesis básica del materialismo histórico, al que hemos tratado como horizonte invariable de los análisis concretos. ¿No supone la adhesión a esa tesis un fundamento extracientifico? ¿Con qué derecho postulamos que debe existir un condicionamiento infraestructural de los textos filosóficos, literarios, etc.? Se ha dicho ${ }^{33}$ que afirmar la pertinencia explicativa de la "base" es formular un "juicio de existencia" sumamente riesgoso que ninguna ciencia está hoy por hoy en condiciones de formular; por lo tanto, si queremos atenernos a un modelo epistemológico canónico debemos abandonar la "tesis básica".

Hay en esta objeción una falacia, que gira en torno al concepto de "juicio de existencia". Dejando de lado los problemas que dicho concepto plantea (ligados a la temática del "compromiso ontológico" y zonas vecinas) digamos que de ninguna manera puede pretenderse que la "tesis básica" sea una especie de "enunciado observacional a priori"; no se trata de eso, sino de una proposición de alto nivel teórico que, como siempre sucede en estos

33 L. Sebag, Marxismo y estructuralismo. México: Siglo XXI, 1969. La crítica de Sebag se hace en el marco del estructuralismo de Lévi-Strauss, y no en el de la epistemologia "académica". 
casos, requiere criterios de confirmación indirecta. Afirmar la tesis es enunciar un fragmento esencial de una teoría general sobre la sociedad, que puede intentarse confirmar o refutar por el rodeo de su poder explicativo y de su aptitud para dar cuenta de los fenómenos sociohistóricos conocidos, y aun para predecir o retrodecir otros hechos del mismo campo. $O$ sea, que su estructura es hipotética y no supone un dogma inmune a toda revisión.

Se dirá quizás que dentro de la epistemologia "académica" han surgido o resurgido puntos de vista que ponen en duda la refutabilidad de tales estructuras teóricas. Pero no necesitamos entrar en debate alguno sobre esa problemática. Porque si toda estructura teórica fundamental es un paradigma que no es posible alterar siguiendo pautas "objetivas" ( $y$ esta tesis no corre por cuenta nuestra) entonces el canon básico del materialismo histórico sigue un destino común a toda teoría, aun la más venerable. No constituye por lo tanto "excentricidad" alguna, expulsable del coto de la actividad científica. Que es precisamente lo que se procuraba mostrar.

Instituto Universttario Pedagógico

JAVter SASSO

Maracay, Venezuela 